\title{
Guidance after twin and singleton neonatal death
}

\author{
Martin de Kleine, Marianne Cuisinier, Louis Kollée, Grietje Bethlehem, Kees de Graauw
}

\begin{abstract}
A study was made to determine whether parents whose newborn twin $(n=72)$ had died differed from bereaved singleton parents $(n=70)$ concerning their satisfaction with professional guidance and care. Most parents felt supported by hospital staff, but the twin parents had fewer avenues of available support, especially after their baby's death. The twin parents' situation requires special attention because they have specific needs that are not always addressed by the current range of available support services. (Arch Dis Child 1995; 36: F125-F126)
\end{abstract}

Keywords: neonatal death, twin, singleton, guidance.

The incidence of twins and higher multiple births is increasing. If a newborn twin dies a very complex situation arises in which contradictory psychological processes occur in all those involved. ${ }^{1}$

\section{Methods}

We investigated bereaved twin and bereaved singleton parents' satisfaction with care and support. We selected all parents who had lost a newborn twin $0.5-3.5$ years earlier from the medical files of five level III neonatal care units. Each twin couple (except for one) was matched with a singleton couple whose baby's birth date approximated most closely to that of the twin parents' newborn and who had lost their singleton baby in the same period.

Of 55 twin couples, $37(67 \%)$ participated in the study by completing a written questionnaire, as did 37 of $54(68 \%)$ singleton couples, giving a total of 142 respondents (72 twin and 70 singleton parents). Department of Clinical of Nijmegen

M Cuisinier

G Bethlehem

Department of Neonatology, University Hospital, Nijmegen L Kollée

Institute for Applied Social Sciences, Nijmegen

K de Graauw

Correspondence to: Dr M Cuisinier, Psychological Laboratory, Department of Clinical Psychology, PO Box 9104 , 6500 HE Nijegen

The Netherlands.

Accepted 28 November 1994

\section{Results}

We found that, in general, twin parents perceived having fewer people in their social network who could understand their feelings about the death of their newborn $(5 \cdot 3$ vs $7 \cdot 1$ persons; $t=-2.93 ; p=0.004)$. Twin parents did not feel any more disappointed by the reactions received than did singleton parents $\left(17 \%\right.$ vs $\left.16 \% ; \chi^{2}=3.50 ; \mathrm{p}=0.477\right)$. About $75 \%$ of the respondents had contacted fellow parents. However, far fewer twin (29\%) than singleton parents $(59 \%)$ found that the contact had been of (very) much use to them; $30 \%$ of the former and $10 \%$ of the latter reported that it had been of little or no use to them $(t=-3 \cdot 76 ; p=0 \cdot 000)$. Most of the twin parents had probably talked to bereaved singleton parents, and not twin parents, as there are no specific support groups for parents who have lost a newborn twin in the Netherlands; there are groups for bereaved singleton parents.

Most parents felt supported by hospital staff. Aftercare was experienced significantly more negatively than support, both when the baby was still alive and at the time of dying and the funeral. Over one third of both groups of parents were predominantly or completely dissatisfied with this.

Mostly, parents were satisfied with the manner in which they had been informed of their baby's likely death. However, twin parents, rather than singleton parents, tended to be advised more often to adopt a positive attitude ( 24 vs $13 \% ; \mathrm{t}=1 \cdot 67 ; \mathrm{p}=0.098$ ).

Following the newborns' death, $90 \%$ of twin and $96 \%$ of singleton patents were predominantly satisfied with the understanding and support of hospital staff $\quad(t=-0.90$; $p=-0.371)$. Less than $10 \%$ felt that caregivers had tried to distract parents' attention from the baby's death, but this tended to happen more often in the twin (7\%) than in the singleton situation $(1 \%)(t=1.65 ; p=0 \cdot 102)$. In general, parents were given ample opportunity to make their farewells.

All parents appeared to have one or more pictures of their deceased newborn. However, only $14 \%$ of twin parents had a picture of the twins together. After the death fewer twin (76\%) compared with singleton (93\%) parents made one or more follow up contacts in hospital $(\mathrm{t}=-2.78 ; \mathrm{p}=0.006) ; 79 \%$ of twin $v s$ $85 \%$ of singleton parents felt predominantly positive about these contacts $(t=-0 \cdot 88$; $\mathrm{p}=0.379)$. Fewer twin (66\%) than singleton $(86 \%)$ parents discussed the loss of their baby with their family physician. They also discussed their loss less frequently with other care givers outside the hospital (28 vs $54 \%$; $\mathrm{t}=-3 \cdot 24 ; \mathrm{p}=0.001)$.

\section{Conclusions}

Differences between twin and singleton substantial, but were all to the twin parents' disadvantage. Compared with earlier studies, parental satisfaction with hospital care seemed to be relatively high. Nevertheless, some improvements are recommended. The loss of a twin has to be taken as seriously as the loss of a singleton, as has been emphasised by others. ${ }^{2}$ Twin parents should be encouraged to express their feelings, however ambivalent. In a sense, parents in their satisfaction with care were not 
these parents experience a double loss: besides their deceased twin, they also miss the specific experience of being the parent of a pair of babies. Attention should be paid to both the dead and the living baby, and it should be suggested to parents that they take pictures of both babies, separately as well as together. ${ }^{2}$ Specific attention is needed regarding the coordination of information when parents have to deal with more than one hospital. Beside hospital follow ups, medical staff should routinely arrange professional support outside the hospital if parents wish it $^{3}$ including an introduction to other bereaved parents of twins.

We thank Mrs M Duijvestijn (University Hospital, Leiden), Dr $\mathrm{R}$ de Leeuw (University Medical Center, Amsterdam), and $\mathrm{Dr}$ J F Samsom (Free University Hospital, Amsterdam), for their contributions to this study.

1 Lewis E, Bryan E. Management of perinatal loss of a twin. BMF 1988; 297: 321-3.

2 Bryan EM. Perinatal bereavement after the loss of one twin. f Perinat Med 1991; suppl 1: 241-5.

3 Rowe J, Clyman R, Green C, Mikkelsen C, Haight J, Ataide L. Follow-up of families who experience a perinatal death. Pediatrics 1978; 62: 166-70. 